\title{
The use of stand-alone fully covered self-expandable metallic stents for drainage of walled-off necrosis or pseudocyst may lead to poor results
}

In current practice, endoscopic transmural drainage is the preferred method for the treatment of symptomatic walled-off necrosis and pseuodocysts in patients with acute pancreatitis [1]. In order to maintain a fistulous tract between these lesions and the gut lumen, fully covered self-expandable metallic stents (FCSEMS) and/or plastic pigtail stents can be used. The migration of FCSEMS to the gut lumen can lead to the disconnection of the cavity from the gut lumen, abscess development in the cavity, and life-threatening septic complications.

We present the case of a 20-year-old man with acute biliary pancreatitis who was admitted to our hospital with abdominal pain, early satiety, nausea, and vomiting. Endoscopic ultrasound and computed tomography scans demonstrated a pseudocyst (diameter $71 \times 126 \mathrm{~mm}$ ) in the tail of the pancreas. The gastric corpus was compressed by the cyst ( $\bullet$ Fig. 1 ). Endoscopic drainage was planned.

Cystogastrostomy was performed and an FCSEMS (Micro-Tech, $16 \times 30 \mathrm{~mm}$; Nanjing, Jiangsu Province, China) was placed into the fistulous tract ( $\bullet$ Fig.2). After the procedure, the patient's symptoms improved. However, he developed fever, leukocytosis, and progressive abdominal pain on the third postoperative day. On plain abdominal radiography, the metal stent was seen to be located in the rectum ( $\bullet$ Fig.3). Endoscopy was performed and large amounts of pus was observed coming from the orifice of the cystogastrostomy into the gastric lumen. A nasocystic drainage catheter was placed into the cyst cavity via the same orifice. The patient expelled the stent on defecation the same day.

Fever and leukocytosis resolved following nasocystic drainage and broad-spectrum antibiotic therapy. The nasocystic drainage catheter was then exchanged for two 10-Fr double-pigtail plastic stents, and the patient was discharged.

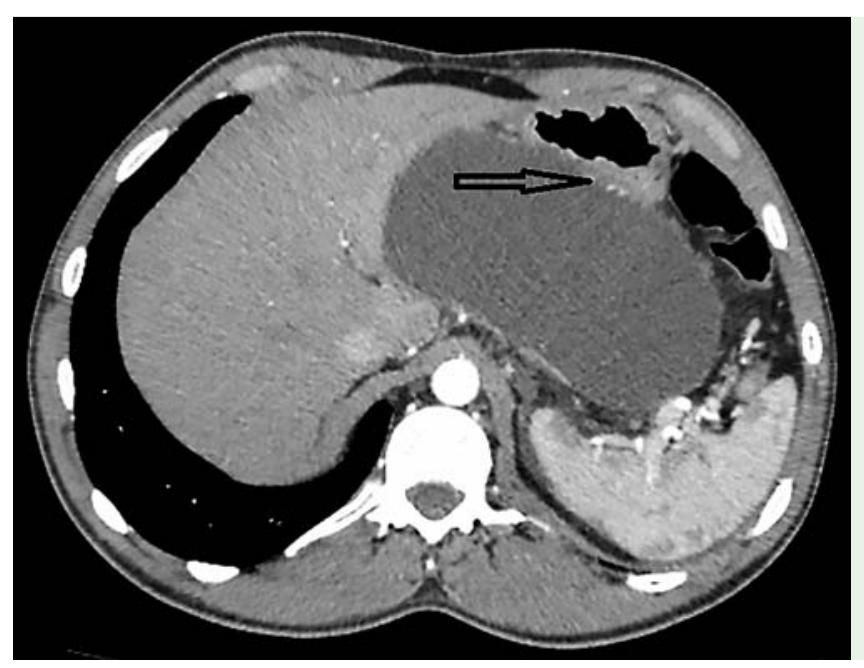

Fig. 1 Computed tomography image of pseduocyst compressing the stomach (arrow).

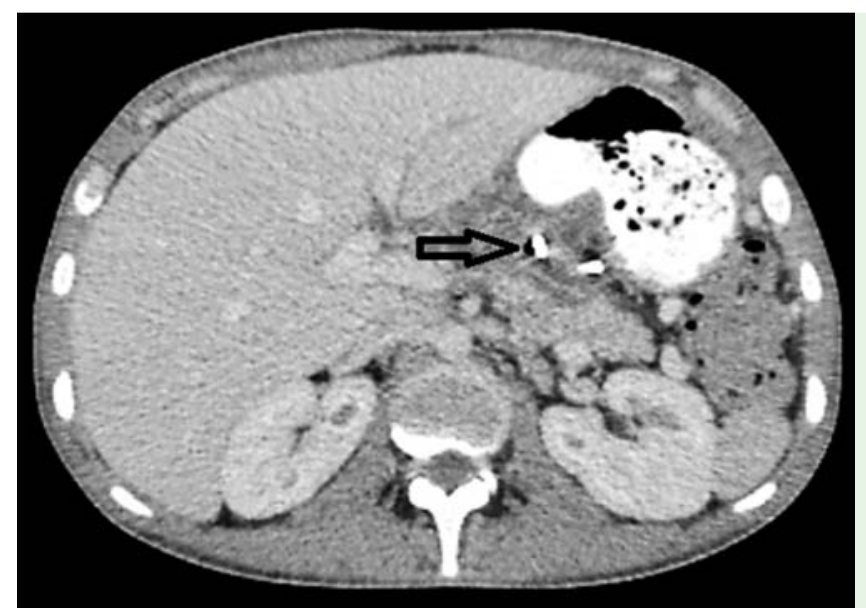

Fig. 2 Computed tomography image of the metal stent (arrow) in the cystogastrostomy.

There are several well-known complications related to the metal stents used in cystogastrostomy. Migration is one of them and can occur either into the cystic cavity or into the gut lumen [2]. It is important to fix FCSEMS in place using a doublepigtail stent (stent-in-stent arrangement) or by the addition of a nasocystic drainage catheter in order to prevent migration and related complications.

Endoscopy_UCTN_Code_CPL_1AL_2AD

Competing interests: None
Bulent Odemis ${ }^{1}$, Erkin Oztas ${ }^{1}$, Muhammet Yener Akpinar', Sabite Kacar' ${ }^{1}$, Ufuk Baris Kuzu ${ }^{1}$, Mustafa Ozdemir ${ }^{2}$

${ }^{1}$ Department of Gastroenterology, Türkiye Yüksek ihtisas Training and Research Hospital, Ankara, Turkey

${ }^{2}$ Department of Radiology, Türkiye Yüksek intisas Training and Research Hospital, Ankara, Turkey 


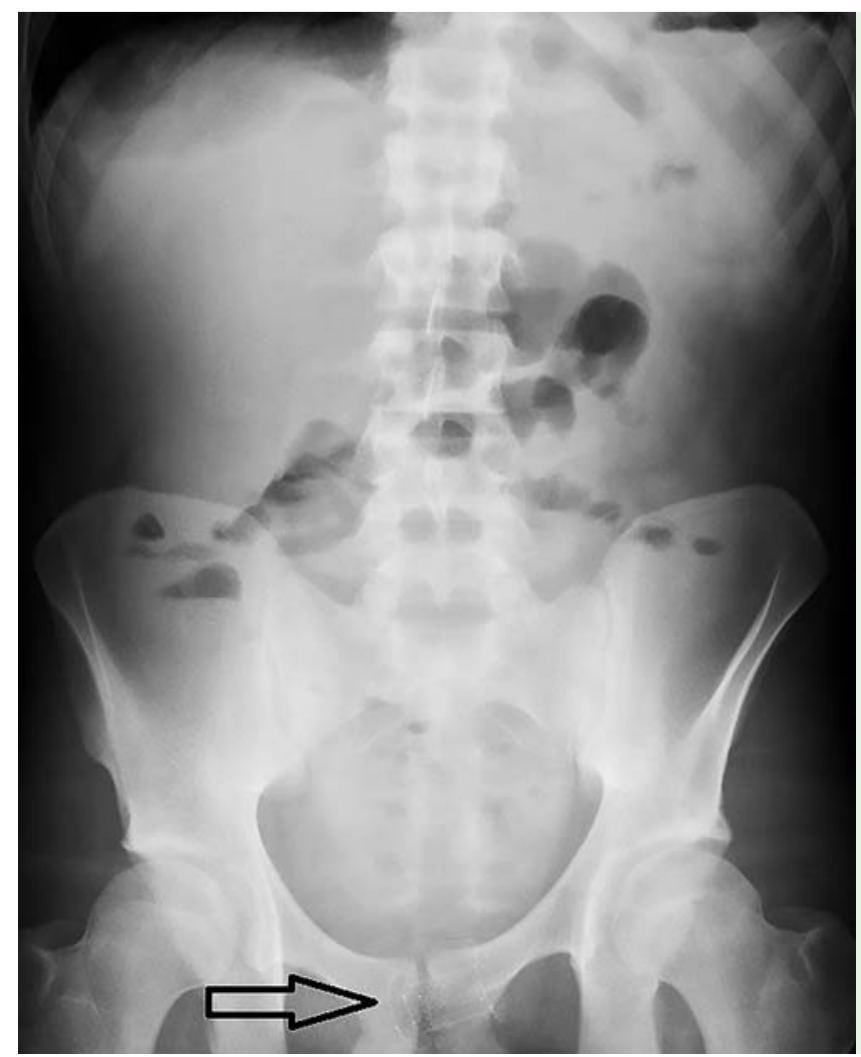

Fig. 3 Metal stent (arrow) in the rectum on plain abdominal radiograph.

\section{References}

1 Schmidt PN, Novovic S, Roug $S$ et al. Endoscopic, transmural drainage and necrosectomy for walled-off pancreatic and peripancreatic necrosis is associated with low mortality - a single-center experience. Scand J Gastroenterol 2015; 50: 611-618

2 Walter D, Will U, Sanchez-Yague A et al. A novel lumen-apposing metal stent for endoscopic ultrasound-guided drainage of pancreatic fluid collections: a prospective cohort study. Endoscopy 2015; 47: 63-67

\section{Bibliography}

DOI http://dx.doi.org/

10.1055/s-0042-112978

Endoscopy 2016; 48: E271-E272

(c) Georg Thieme Verlag KG

Stuttgart · New York

ISSN 0013-726X

\section{Corresponding author}

\section{Muhammet Yener Akpinar, MD}

Türkiye Yüksek İhtisas Training

and Research Hospital

Kızilay Street

Sihhiye

Ankara 06100

Turkey

Fax: +90-312-3124120

muhammet.yener@gmail.com 